\title{
NÓS E A MORTE - UM ESTUDO PSICOLÓGICO "Sivis vitam, para mortem"
}

\author{
Maria Margarida da Cunha Gonçalves*
}

GONÇALVES, M.M.C. Nós e a morte: um estudo psicologico. Rev.Esc.Enf.USP., v.28, n.3. p. 243-50, dez. 1994.

Partindo de um artigo inédito de Freud escrito em 1915, a autora estabelece comparaçỏes em relação ao comportamento humano frente a situaçóes de morte, tendo em vista suas experiências $e$ vivências adquiridas nos campos da Enfermagem $e$ Psicologia.

UNITERMOS: Morte. Psicanálise.

\section{UM ACONTECIMENTO.....}

Estava eu prestando cuidados de enfermagem a uma paciente que se encontrava numa enfermaria com aproximadamente oito leitos, quando a porta se abre.

Entram alguns médicos, estudantes de medicina, professores. Aproximam-se do leito vizinho à da paciente que eu cuidava, onde se encontrava recostada. Era uma enfermaria de pacientes portadores de cardiopatias.

Aluna de enfermagem, cursava a cadeira de Fundamentos e estava indo para o hospital, penso, pela segunda ou terceira vez.

Ouvi um dos médicos dizer para os demais que aquela senhora era portadora de uma certa afeç̧ão cardíaca, achava que ela estava bem naquela manhã, com bom aspecto. Disse algo como verificar sua capacidade pulmonar. Deu a ela um tubo com um medidor em uma das extremidades e pediu para que soprasse. E assim ela o fez.

Foi soprando.

E eu, curiosa, ia observando meio de esguelha aquela cena. A paciente foi me parecendo estar ficando cansada, como que meio arroxeada, mas todas ali naquela enfermaria tinham os lábios e as unhas tão escuras.

De repente, ela agitou-se, arregalou os olhos, fez um grande esforço para respirar e em seguida deixou cairem os braços sobre o colo, as mãos soltaram

* Enfermeira. Psicologa Clinica. 
o tubo, a cabeça se apoiou no travesseiro, fechou os olhos e morreu. No ato, tudo muito rápido.

$O$ médico que a orientara, penso, ficou um tanto surpreso. $E$ eu, já não estava assustada, estava literalmente paralisada. Queria sair do lugar e não conseguia. O mesmo médico a examinou, outros também o fizeram, desceram a cabeceira da cama. Chamaram pessoas da enfermagem. Trouxeram uma tábua, colocaram-na sob a paciente, sopraram em sua boca, amassaram seu tórax, deram-lhe oxigènio.

Eu ainda com os pés grudados no chāo.

Agora, já não havia na enfermaria qualquer estudante, médico ou professor. Somente os olhos assustados das várias mulheres cardiacas como aquela senhora. $E$ eu, com um jarro de água na mão, aturdida, catatônica.

Neste momento dei-me conta que também jả não havia ali, ninguém da enfermagem. $E$ aquela mulher já sem vida, inerte no leito.

Eu a cumprimentara, brincara com ela como fizera com os demais pacientes naquela manhā.

E agora só se escutava o silêncio. Brutal. Meu coração batia forte, senti tonturas. Consegui finalmente sair dali e fui para um canto da sala de serviço e chorei. Dizia pra mim mesma que nào mais iria ser enfermeira. Sim, claro, iria desistir naquele mesmo momento.

Senti uma mão no meu ombro, depois afagou minha cabeça. Era Wanda Horta, minha instrutora. Levantei os olhos e vi o seu olhar suave me observando. Com muita doçura, deixou-me chorar.

Comecei então a sentir uma emoção diferente, percebia-me ainda viva. Eu continuava viva, não morrera. E como devem deduzir, não desisti do curso.

Hoje estas lembranças me são extremamente caras, preciosas.

Havia entrada em contacto com a morte como nunca experienciara antes. A sensação era terrível. Via-me assim, colocada naquele momento, frente a frente com a minha onipotência (penso que me imaginara eterna), minha vulnerabilidade e finitude. Colocada entre aquilo que eu fantasiava $e$ aquela durissima realidade.

\section{OUTRO ACONTECIMENTO....}

Hoje, vinte e cinco anos passados, um longo periodo de experiências, alegrias, decep̧̧ōes.

Um distanciamento longo da Enfermagem e um regresso a ela. Neste periodo ausente, um curso de Psicologia e um contacto estreito com a Psicanálise.

E uma nova (e ao mesmo tempo antiga) experiência me surpreende.

Estava trabalhando numa enfermaria de pacientes portadores de hepatopatias, após ter deixado de trabalhar no campo como enfermeira por quatorze anos, quando percebi, ao chegar pela manhà, que um dos pacientes apresentava hematèmese. Um sangramento constante e abundante. Avisado o médico, foi prescrito um soro, ligado a seguir. Passaram um intracath. E o paciente continuou sangrando até entrar em choque. 
E toda aquela confusão de novo.

Médicos, enfermagem, tubos, tábuas, oxigènio, endoscópio, Bird, sonda com balào para varizes de esōfago, massagem cardiaca e morte.

Todos saem do quarto. E o paciente permanece ali, inerte e nu, com o endoscópio ainda na boca, sangue por todo o quarto: no chão, nos lençois, na parede.

Olho aquela cena. Em seguida pego um lençol e cubro o paciente que parecia ainda enxergar, com os olhos bem abertos. Tudo muito brutal. Parece que revivo tudo de novo. Será que algo mudou dentro de mim nestes anos todos de convivência com minhas fantasias e realidades?

Penso que sim. Muitas coisas mudaram. Mas um questionamento me leva a pensar com mais cuidado e carinho sobre todas estas questōes.

A equipe de Enfermagem entra no quarto, limpa, prepara o corpo, tudo muito profissional, conversando, contando das coisas acontecidas em casa, na rua. Tamponam, lavam, esparadrapam, cobrem, enrolam, tudo pronto. Mais uma rotina cumprida. Aquele paciente já está esquecido.

A equipe médica corre, entuba, faz massagens. perfura, fura, tudo como num filme do Carlitos. Bastante acelerado. Fizeram o que foi possivel. Tudo muito profissional. Depois tomam cafezinho, falam dos filhos. da namorada, da última aplicação no mercado financeiro, do lançamento de um modelo de carro importado. Aquele paciente já está esquecido.

Quando será o próximo?

Eu já não fico paralisada, nào verto lágrimas, mas me sinto tocada (e penso que ainda bem!), com estas situaçōes. Recuso-me internamente a ser tão profissional assim. Penso que até seria bom tentar lidar com estas situaçōes de forma tão asséptica, distante dos sentimentos, dos questionamentos, das indagaçōes.

$E$ penso que, por estas razóes que permanecem rebolando inquietas e fervilhantes dentro de mim é que me proponho a colocar no papel, desta forma tào pessoal, os meus pensamentos.

\section{MAIS UM ACONTECIMENTO.....}

-"Minha màe precisa ser internada aqui na clínica, o médico disse que é urgente, acho que vai precisar ser operada. Ela nào aguenta quando the tocam o abdome. sente dor. Ela já esta no Pronto-Socorro. Precisaria de um leito para ela aqui".

Quem relata esta situaçào é uma funcionária da propria clínica onde trabalhava como escriturária. Uma pessoa muito estimada pelos colegas. Parecia bastante ansiosa e extremamente aflita.

Presenciei estes acontecimentos quando acompanhava alunas de Enfermagem. no cámpo de Estágio.

A màe da funcionária foi internada, operada e por condiçòes da propria evoluçào de sua moléstia, veio a falecer. 
Neste episódio, o que se observou foi uma dedicação plena dos funcionários em geral, dos alunos, dos médicos. A conduta tão aparentemente fria e profissional das situaçōes de morte "de rotina", não se evidenciou.

Praticamente toda equipe "ligadíssima" na colega e em sua mãe. Cuidados, desvelos, visitas frequentes ao leito da paciente, tanto durante a fase em que ficou internada, como quando ocorreu seu falecimento.

Primeiramente incentivos, oraf̧ōes, esperança. Depois lágrimas, lamentos, cuidados aprimorados com o corpo, missa, palavras de consolo. A Clínica silenciosa e de luto.

\section{CONSIDERAÇŌES TEÓRICAS}

A vida e a morte, sua interação e inter-relação têm sido, sem dúvida, um dos pontos centrais da teoria psicanalítica.

Sigmund Freud em seu ensaio denominado "Os instintos e suas vicissitudes"(1), centraliza suas observações principalmente sobre os impulsos (pulsões) humanos.

Estas pulsões são traduzidas por aquilo que se conhece como desejos, que são anseios inerentes à vida humana. A realização dos desejos ou a tentativa de sua efetivação, pode até vir a se dar de forma consciente, porém se originam do inconsciente da mente. Seriam, portanto, realizações ou a sua busca, as quais, muitas vezes não se alcança o significado (ou motivação interna).

Inicialmente Freud acreditava que poderia existir uma gama enorme destas forças internas, mas posteriormente as englobou em duas principais: EROS (do grego AMOR) e TÂNATOS (do grupo MORTE). EROS, seria o desejo de viver e amar e TÂNATOS, o desejo de morrer e de matar.

Os sentimentos (emoções), pensamentos e sonhos foram os pontos elegidos por ele para o estudo que culminou pela construção de sua complexa teoria da personalidade humana.

Recentemente chega-nos às mãos, um artigo inédito de Freud, datado de 1915 intitulado "Nós e a Morte"(3). Este artigo baseia-se em uma conferência por ele proferida, por volta do início da primeira guerra mundial. A leitura deste texto parece ter suscitado em mim recordações e pontos de reflexão que me proponho a analisar.

Ele inicia sua conferência dizendo que iria falar sobre um tema delicado e perturbador. Que se percebia assim como às demais pessoas, lidando com a morte como se fosse algo estranho, tentando eliminar sua percepção de suas vidas.

Mas, continua, a morte se faz presente mesmo que ocorra a uma certa distância de nós quando, por exemplo, se tem notícia de algum acidente como um incêndio onde morrem muitas pessoas.

Fica-se, porém, mais tocado, quando falece alguém de nosso círculo de amizade. Os sentimentos são de luto mas logo se encontra um motivo para tal ocorrència: a pessoa não se cuidou direito, não procurou um médico a tempo, ou então foi um castigo ou uma fatalidade. 
Segundo a escola psicanalítica, pode-se observar que no fundo de cada um de nós, não se crê na própria morte. Nem sequer a podemos imaginar. Quando se tenta pensar como ela se dará, quem chorará por nós, se está participando dela como simples expectadores. Existe uma crença de que só pensa na morte do outro quem é mau. Pessoas muito sensiveis e, portanto, melhores (como todos nos imaginamos), resistem a estes pensamentos. Se eventualmente uma pessoa vem a falecer, passa-se a admirá-la como a um herói, "que foi capaz de uma façanha extraordinária", diz Freud.

Ao iniciar este artigo, ao relatar minha primeira experiência com a morte de forma tão próxima, penso que meus sentimentos, naquele momento se aproximavam destas observaçōes de Freud. Eu não poderia imaginar-me na situação da paciente. Quem sabe, até aquela data, eu tentara afastar o pensamento perturbador da morte para bem longe e naquele momento via-me diante do fato consumado. Aquela paciente encarara a morte e eu não podia continuar fugindo da sua percepção. Fora próximo demais para não ver. Penso que cheguei a ficar perturbada, em luta interna contra a idéia da infinitude que eu até então alimentara e a da presença real da finitude. Constatava que, se ela morre então eu também posso morrer. Ou será que já morrí? Por alguns instantes fiquei em estado de choque. Identificada com ela e em dúvida. Só algum tempo depois pude, quem sabe, separar-me. E senti depois que era suportável pensar na morte. Mas ainda a morte do outro e protegida por uma certa distância afetiva.

Voltando à conferência proferida por Freud, observa-se a seguinte afirmação: "fica-se colocado em uma posição indefesa quando a morte ceifa uma pessoa querida e próxima, como a mãe, o pai, esposo, filho, irmão ou amigo". E continua dizendo que, ao se observar esta pessoa, ou a nossa pessoa nesta mesma situação, a impressão é a de que se sepulta com ela toda nossa esperança. Nada nos consola e resiste-se ao máximo substituir por outra, a pessoa objeto do nosso amor. Neste sentido a sensação é a de que a morte empobrece a vida e nos torna covardes. E, diz ele, tem-se uma conviç̧ão de que não nos importaríamos com o evento morte se ela não pusesse fim à própria existência. Esta perda da própria vida, é observada agora na perda do ente querido, com o qual parece que se enterrou uma parte de nós mesmos.

Neste sentido, reporto-me ao terceiro acontecimento descrito neste artigo, onde se pode observar a morte bem mais próxima. Uma parte de cada um se identifica com o sofrimento da pessoa amiga e querida. Parecia que um pouco de cada uma das pessoas estava morrendo junto com a mãe da colega. Chorou-se, fez-se luto, sofreu-se de melancolia. Foi um comportamento individual e grupal bastante diferente do segundo acontecimento narrado onde o paciente é um desconhecido e, portanto, o contacto com sua perda pareceu mais fácil de ser negado e consequentemente suportado. Seria alguém que não nos diz respeito diretamente, permanecendo afastado dos sentimentos afetivos. Desta maneira pode-se proceder como quando se toma conhecimento de que houve um terremoto no México ou Los Angeles ou que o Edifício Joelma incendiou-se. 
O que se ressalta é que não é possível negar o fato. A ocorrência da morte fica registrada dentro de nós mesmos, podendo-se não sofrer com o afastamento da idéia de que isto pode ocorrer com nossa pessoa. Desta forma, o morto se transforma em algo que não nos diz respeito. Penso que esta é uma forma, um "jeito" dado pelo inconsciente para que se possa continuar acreditando na própria imortalidade. Uma forma quase que inevitável de entrar em contacto com a morte sem morrer junto, o que leva o profissional a dar sequência ao seu trabalho sem muito sofrimento. As demais pessoas podem morrer; mas precisa-se continuar vivo, falando das coisas da vida, do trânsito que está um ', da política que é sempre desonesta, da situação econômica que está insuportável, e assim por diante. É necessário se estar presente para participar da vida (eternamente!).

Mesmo quando se trata da morte de um parente mais próximo, após algum tempo de luto ressuscita-se e assim estaremos reforçando a crença inconsciente na mossa imortalidade.

Voltando agora àquela colocação de Freud de que a morte seria mais aceitável se ela não pusesse fim à própria vida, ele cita um modelo: "é pena que na vida não aconteça como o que se passa em uma partida de xadrez, onde um movimento em falso nos obriga a concluir uma partida. A diferença é que no xadrez pode-se começar outra partida, partir para uma revanche".(2)

A partir deste ponto do texto, o autor traz uma visão histórica de como o homem primitivo encarava a morte e o seu legado, que permanece até os dias atuais.

Segundo ele, o homem pré-histórico tinha uma visão diferente e até contraditória a respeito de sua própria morte e a do outro. A morte do outro, do inimigo, do desconhecido lhe parecia boa, a entendia como extermínio e a buscava. Assassinava com prazer e naturalidade.

Contudo, em relação a si mesmo, via a morte tão irreal e inimaginável, como é ainda hoje para cada um de nós.

Estas duas colocações opostas colocaram o homem em um conflito que teve importante repercussão interna. Este conflito se instalava quando o homem primitivo via morrer um familiar ou amigo que ele amava intensamente, como a si próprio. Neste momento ocorria uma experiência emocional desagradável que lhe acenava com a possibilidade dele vir a morrer, já que cada ser querido era parte do seu próprio ego. (2)

Segundo Freud ${ }^{(2)}$, junto ao corpo do ente querido se formou não só a doutrina da alma e a crença na imortalidade, mas também a consciência da culpa, o medo da morte e as primeiras normas éticas.

Segundo a psicanálise, a consciência da culpa surgiria do sentimento ambíguo a respeito do morto: o medo de morrer pela identificação com ele e ao mesmo tempo perceber que apesar da sua morte permanecemos vivos. $O$ fato de permanecermos vivos, e isto é um fato inegável, reforçaria no inconsciente de cada um a idéia ou a crença na própria imortalidade.

E parece que os homens modernos não puderam resolver esta contradif̧ão. "Não matarás" é o dogma ético mais antigo e ainda hoje vigente. Segundo 
o autor, foi concebido junto ao corpo do ente amado e estendido lentamente ao não amado e por fim ao inimigo, através do sentimento da culpa.

Os primitivos quando voltavam de uma batalha, não deveriam pisar 0 chão de sua casa ou ver o rosto de sua mulher ou filhos antes de haver expiado seus assassinatos, através de penosas e longas penitências.

Indaga então Freud: "como se comporta nosso inconsciente, escondido nas profundezas da alma frente à questão morte?" E a seguir responde, dizendo: "nosso inconsciente assume hoje a mesma posição que o homem pré-histórico. Tanto neste aspecto como em tantos outros, ele perdura em cada um, invariavelmente. Está obrigado a comportar-se como imortal e é possível até que este seja o segredo do heroísmo. O herói seria aquele que se deixa levar pela crença na imortalidade ditada pelo inconsciente. $O$ medo da morte que se sente mais frequentemente do que imaginamos, é uma contradição ilógica desta certeza. $E$ a esse respeito conta uma anedota de um marido que diz para sua mulher: "se um de nós morrer, vou viver em Paris".(2)

Diz Freud ${ }^{(2)}$ que os filósofos sustentavam que o enigma intelectual que a morte supunha para o homem primitivo, teria sido o marco para a sua reflexão e o ponto de partida para a especulaçāo sobre o seu significado.

Considera ele, contudo, que não foi o enigma intelectual mas o conflito emocional que aparece quando falece uma pessoa querida, que deu origem à tentativa humana de buscar uma compreensão da morte.

Com a percepção da perda do outro, o homem primitivo inventa os espíritos, pensa na divisão do Homem em corpo e alma. A recordação do defunto deu lugar a outras formas de existir para as quais a morte é só o início de outra vida depois da morte aparente.

Muito mais tarde as religiōes foram capazes de transformar uma existência posterior na mais preciosa e bondosa forma de existir e de menosprezar a vida concluída pela morte, como meramente preparatória.

No final, questiona Freud(2) "não deveria admitir que há uma superestimação psicológica a partir desta posição cultural sobre a morte e que até seria muito produtivo se se pudesse admitir a verdade? Não seria melhor colocar a morte, tanto em nossa realidade como nos pensamentos, no seu lugar correspondente?"

$\mathrm{E}$ continua dizendo: "penso que isto poderia tornar a vida mais suportável e este é o dever de todo ser humano. Na escola se aprende uma lema político dos antigos latinos que dizia: "Se queres conservar a paz, prepara a guerra". Se poderia adaptar este provérbio ao nosso tema presente: Se queres suportar a vida, prepara-te para a morte".

Interessante é notar como Freud chama a atenção no final de sua palestra ${ }^{(2)}$, para o fato de se tentar colocar a idéia da morte em seu lugar real na nossa existência.

A morte existe, é consequência da própria vida, todos morrem e as pessoas podem se preparar psicologicamente para isto.

Esta seria uma posição intermediária entre a de "negar" parcialmente que ela existe e é real e aquela que leva cada um a morrer um pouco junto 
com o ente querido. Esta última, percebida como posição melancólica, é extremamente desprazeirosa para o ego.

A tentativa de elaboração de que nāo se é eterno como se gostaria, mas que somos vulneráveis e finitos, não deixa de ser uma tomada de consciência que poderia nos levar a viver melhor estas experiências que estão presentes na vida pessoal e profissional das pessoas.

GONÇALVES, M.M.C. We and the dead: a psycologycal study. Rev.Esc.Enf.USP., v.28, n.3, p. 243-50, dec. 1994.

Based upon a unpublished paper from 1915, the author settles comparahison soncerning to the human behavior facing death situations, based upo her's own experiences, adquired in Nursing and Psychology areas.

UNITERMS: Death. Psychoanalisis.

\section{REFERÊNCIA BIBLIOGRÁFICA}

. FREUD, S. A História do Movimento Psicanalitico. obras completas, Rio de Janeiro, Imago, 1969, v.19: Os instintos e suas vicissitudes.

. BOLETIM INFORMATIVO DA FEDERAÇĀO PSICANALITICA DA AMÉRICA LATINA (FEPAL). Maldonado, 1991. 